\title{
Investigation on Implemental System of Provincial Emergency Plan for Unexpected Geological Disasters in Shaanxi Province
}

\author{
Yanlin Wang ${ }^{1}$, Chunyu Bu ${ }^{2}$, Jingyi Liu ${ }^{2}$, Chengfang Zhang ${ }^{2}$, Zhen $\mathrm{Qi}^{1}$, Weizhong $\mathrm{He}^{3}$ \\ ${ }^{1}$ Division of Geo-Environment, Shaanxi Bureau of Land and Resources, Xi'an 710082,China \\ ${ }^{2}$ College of Geology Engineering and Geomatic, Chang'an University, Xi'an 710054, China \\ ${ }^{3}$ Shaanxi Institute of Geo-environment Monitoring, Xi'an 710054,China
}

\section{陕西省省级突发地质灾害应急预案实施体系探讨}

\author{
王雁林 ${ }^{1}$, 卜春昱 ${ }^{2}$, 刘静神 ${ }^{2}$, 张成芳 ${ }^{2}$, 齐震 ${ }^{1}$, 贺卫中 ${ }^{3}$ \\ ${ }^{1}$ 陕西省国土资源厅地质环境处, 陕西西安 710082, 中国 \\ 2 长安大学地质工程与测绘工程学院, 陕西西安 710054, 中国 \\ ${ }^{3}$ 陕西省地质环境监测总站地质灾害防治室, 陕西西安 710054, 中国
}

\begin{abstract}
This paper points out problems in the implementation of emergency plan for geological disasters in Shaanxi Province by analyzing typical cases in recent years. Drawing lessons from emergency management theory at home and abroad and using systematology, three-stage implemental system of provincial emergency plan for geological disasters is put forward in this paper. This investigation not only has practical values in revising current emergency plan for geological disasters, but also plays a promoting role for geological disaster prevention and control theory.
\end{abstract}

Keywords: geological disasters; emergency plan; management

摘要

通过对近年来陕西省重大地质灾害应 急典型案例的分析, 指出了陕西省地质灾 害应急预案实施中存在的问题。借鉴国内 外有关应急管理理论, 运用系统论, 提出
了构建省级地质灾害应急预案三级实施体 系。本文研究不仅对于指导当前的地质灾 害应急预案修编具有实用价值, 对于地质 灾害防治理论也有一定的推动作用。 关键词: 地质灾害; 应急预案; 管理

\section{1. 引言}

陕西省于 2005 年、2010 年先后编制发 布了两次省级突发地质灾害应急预案 ${ }^{[1][2]}$ 。 预案发布后在规范省级地质灾害应急方面 发挥了重大作用, 而且对推动市、县级地 质灾害应急预案编制与实施工作起到了引 导与规范作用。2016 年进行第三次修编工 作, 目前修编工作基本完成。笔者先后参 与了陕西省这三次应急预案编制工作, 通 过 10 多年的应急预案管理与实践经验, 笔 者认为地质灾害应急预案修编过程是对地 质灾害应急工作认识不断深入的过程, 地 质灾害应急管理工作的核心是围绕应急预 案准备、实施、总结评估的管理过程。地 质灾害应急预案修编及实施必须用系统观 点, 形成实施体系。全国新一轮省、市、 县都即将进入突发地质灾害应急预案修编 阶段, 如何科学合理修编应急预案并建立 
有效的实施体系, 是当前地质灾害应急管 理中亟待解决的问题。本文提出了构建省 级地质灾害应急预案三级实施体系的思 路、内容, 这一预案实施体系不仅对省级 层面细化应急预案实施具有一定指导作 用, 对于市县两级地方政府和部门完善应 急预案也有一定的借鉴价值。

\section{2. 地质灾害应急预案的实施存在的主要 问题}

两轮地质灾害应急预案发布后, 发挥 了重要作用, 但在实施中也存在需要改进 的问题:

一是预案缺乏实施体系。地质灾害应 急实践中, 一旦突发地质灾害, 立即启动 预案, 这种长期的实践, 形成了把应急响 应简化为启动预案的简单化认识。重大应 急实践表明, 启动预案是预案实施的第一 阶段。启动预案后, 实施、总结评估还有 一系列的过程。在实施环节, 还包括应急 调查、医疗卫生、安置救助等横向的实施 协调工作。而目前应急预案, 还缺乏相应 配套的实施制度。

二是预案实施中的组织架构与应急工 作中的处置架构缺乏衔接。预案的组织结 构是以部门为单位的, 2005、2010 年陕西 省发布的突发地质灾害应急预案, 从其组 织机构上成立了突发地质灾害应急指挥 部, 有若干个部门组成成员单位, 各组成 部门少则 10 余个, 多则 30 多个, 这些部门 都明确了各自职责。而在地质灾害应急过 程中, 是围绕应急中的事权进行划分的, 这些事权包括成因调查、交通管制、抢险 救援等基本的应急处置工作。这种人与事 的不对等, 形成了组织结构大、实际运行 少的构架，实践中没有发挥应用的作用。 2015 年山阳 8.12 山体滑坡应急和 2017 年 4.17 白河崩塌应急中, 主要参与部门有 10 个左右。充分说明了应急机构的架构需要 调整。

三是应急预案的横向层面、纵向层级 之间关联性不强。以往的省级应急预案组 织单位以部门为主, 部门与部门之间是平 等配合关系, 部门之间没有没有形成相对 固定的关系, 往往在应急过程中需要临时
组建, 这种临时组建的应急工作组模式有 其灵活的一面, 但其日常工作中的衔接就 十分松散, 没有明确的制度要求, 缺乏经 常性演练, 往往事发后才形成关系, 不利 于整体效果。从纵向上, 目前围绕着省级 应急预案的细化, 各部门的职责的细化落 实并没有制度上的要求, 造成部门在具体 实施应急预案中资源调动、应急处置等方 面有差异很大。

\section{3. 健全完善省级地质灾害应急预案体系 的思路、内容}

通过对省级地质灾害应急预案编制与 实施中存在问题的分析, 需要对省级地质 灾害应急预案编制及其实施进行完善。完 善思路是按照系统、有序、高效的构建省 级地质灾害应急预案三级实施体系。其要 点包括: 一是灾害应急是围绕着最短时 间、最大效果而展开的紧急状态下的特殊 活动, 包括现场抢险救灾、交通管制、医 疗防疫、灾民救助、调查评估等工作, 每 项工作都包括几个主要部门, 因此建立以 组为单位的应急机制比部门更加有效。二 是在组基础上, 形成一级以政府预案为总 预案、二级以组建立响应分预案、三级为 部门处置预案的三级实施体系, 形成横向 关联、纵向协调的实施体系; 三是无论是 政府、组、部门都要构建从应急准备、应 急实施、应急评估三个阶段的应急预案全 过程的处置体系。具体如图 1。

\section{4. 省级地质灾害应急预案实施体系中需 要注意的问题}

构建省级地质灾害应急预案实施体系 是个探索的过程, 需要做好如下方面:

(1) 建立健全相关制度。在省级突发 地质灾害应急预案作为总预案的基础上, 从两个方面做好实施体系制度建设工作。 一是应急预案本身, 需要建立应急预案准 备、应急预案实施、应急预案评估制度。 二是围绕应急预案实施的体系建设工作。 应急预案机构下设若干组, 每个组都要围 绕应急总预案, 编制具体分预案, 再由部 门编制具体响应预案, 确保三级实施体 系。 


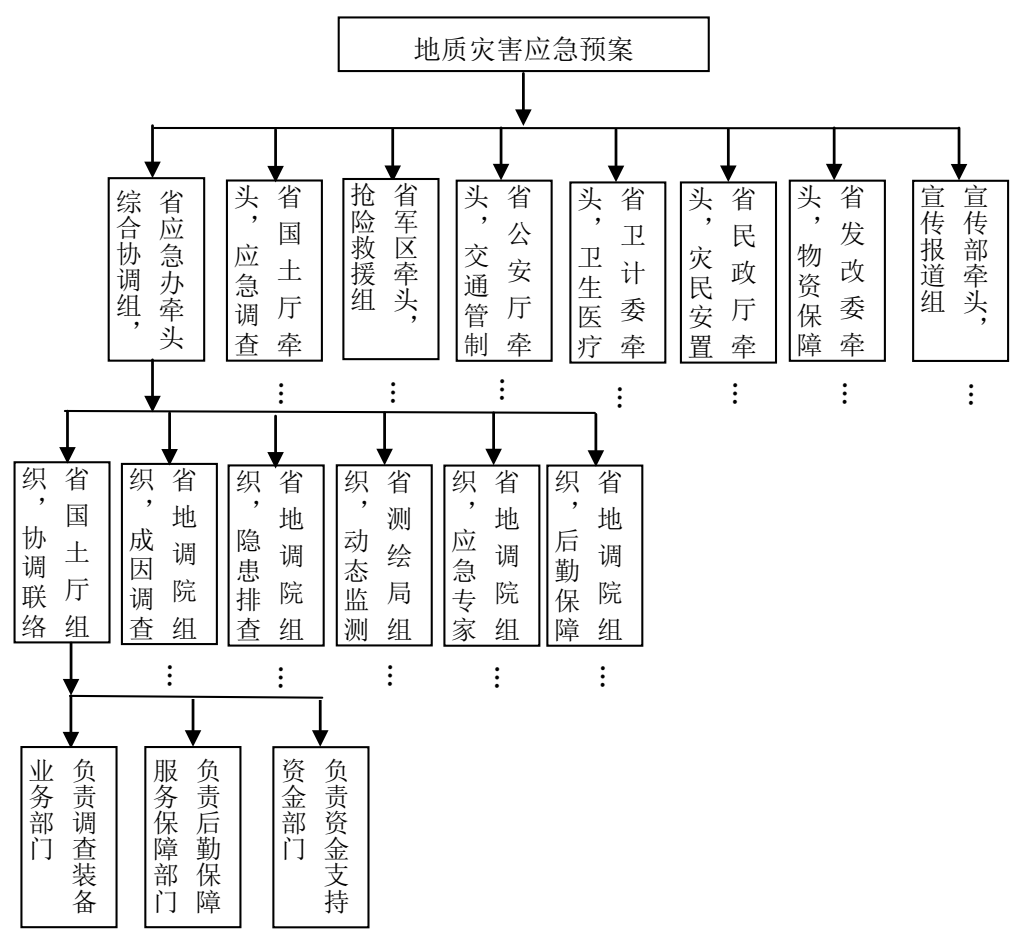

图 1. 省级突发地质灾害应急预案三级实施体系

（2）建立健全应急管理机构与技术支 撑体系。健全省级地质灾害应急管理机 构, 推进地质灾害应急管理指挥中心有效 运转; 支持组建省地质灾害应急技术指导 中心, 配置精干、高效、强有力的科技队 伍, 配置先进的应急调查设备、监测、预 警设备, 服务地质灾害应急管理工作。

(3) 加强应急演练与应急评估工作。 三级实施体系的每类预案都应进行必要演 练, 确保一旦应急, 可以及时高效运转。 做好应急事件的事后评估工作, 针对薄弱 环节, 及时改进完善。

\section{参考文献}

[1] 范立民, 陕西环境地质研究——2014 年 陕西省地质灾害防治学术研讨会论文 集, 中国地质大学出版社, 北京, 2014.
[2] 王雁林, 郝俊卿, 赵法锁等, 地质灾害风 险评价与管理研究, 科学出版社, 北京, 2014.

[3] 游志斌, 薛澜.美国应急管理体系重构新 趋向:全国准备与核心能力, 国家行政学 院学报, 2015.

[4] 中华人民共和国突发事件应对法 [EB/OL].(2007-08-01)[2015-1001].http://www.gov.cn.

[5] 廖声银, 江鸿涁. 初论突发地质灾害应急 预案的管理, 中国地质灾害与防治学 报, 20(4):110-112, 2009.

[6] 张小趁, 陈红旗. 突发地质灾害应急预案 建构模式研究, 人民长江, 47(18):1-4, 2016.

[7] 张小趁, 陈红旗.突发地质灾害应急技术: 过程模式, 灾害学, 30(4):149-155, 2015.

[8] 连建发, 国家突发地质灾害应急预案评 估研究, 西部探矿工程, (12):109-111, 2015. 
[9] 陈红旗, 徐永强, 庄茂国等. 地质灾害应 急支撑体系建设基本问题分析, 中国地 质灾害防治学报, 22(4):108-111, 2011.

[10] 刘传正.重大突发地质灾害应急处置的 基本问题, 自然灾害学报, 15(3):2430,2006.

[11] 龙世洪.重大地质灾害应急处置实践与 思考, 资源环境与工程, 21(6):654-657, 2007.

[12] 邱维理, 庄茂国, 张旭阳等.美国地质灾 害应急响应体系管窥与启示, 中国地质 灾害与防治学报, 27(3):127-137, 2016.

[13] 张小趁, 陈红旗.突发地质灾害应急响 应: 避险模式研究, 中国安全生产科学 技术, 11(9):57-62, 2015.

[14] 冯春涛, 地质灾害应急管理相关问题研 究, 现代矿业, (10):113-116, 2014.

[15] A. Kozak, Risk Management in Process Industry - Practical Approach in Poland, Journal of Risk Analysis and Crisis Response, 1(2): 102-105, 2011.

[16] A. Pan, A Study on Residents' Risk Perception in Abrupt Geological Hazard, Journal of Risk Analysis and Crisis Response, 2(1): 44-55, 2012. 